\title{
LA CALIFICACIÓN DEL CONCURSO POR IRREGULARIDADES CONTABLES GRAVES, INEXACTITUD GRAVE DE DOCUMENTOS APORTADOS Y RETRASO EN LA SOLICITUD DEL CONCURSO DESDE UNA VISIÓN JURISPRUDENCIAL
}

\author{
María del Pino Domínguez CABRERA \\ PROFESORA CONTRATADO DOCTOR DE DERECHO MERCANTIL \\ UniversidAd DE LAS PALMAS DE GRAN CANARIA
}

SumARIo: I. Introducción. II. Delimitación del objeto. III. Supuesto de irregularidad contable. IV. Inexactitud grave en los documentos acompañados a la solicitud de declaración de concurso. V. El retraso en la solicitud de concurso. VI. Elementos subjetivos. VII. Conclusiones. VIII. Bibliografía

RESUMEN: La práctica ha ido modulando el desarrollo legislativo de la Ley concursal española, que sin duda, supone una novedad en atención a lo que venía siendo habitual.

Ciertamente, hoy su desarrollo legislativo ha venido matizado por la rapidez en sus modificaciones y lo que parece que va afectando al encaje general de una norma, que fue trabajada por las Comisiones de juristas. Dicho esto, ciertamente la doctrina y jurisprudencia marcan la importancia en su evolución, así en ámbitos tan importantes como la calificación concursal, el encaje conjunto es imprescindible para entender una parcela compleja pero apasionante de la insolvencia empresarial.

Palabras Claves: concurso, calificación concursal, irregularidades contables graves, inexactitud de la documentación, retraso en la solicitud concursal.

ABSTRACT: The practice has been modulating the legislative development of the Spanish Insolvency Law, which certainly is a novelty in attention to what had been customary. Certainly, today its legislative development has been tempered by the speed of their modifications and what looks affecting the overall fit of a standard, which was worked by the Commissions of jurists. That said, the doctrine and jurisprudence certainly mark the importance trends, and in such important areas as bankruptcy rating, all lace is essential to understand a complex but exciting plot of corporate insolvency.

KEYWORDS: calificación concursal, irregularidades contables graves, inexactitud de la documentación, retraso en la solicitud concursal. 


\section{Introducción}

Por la Administración Concursal se solicita la calificación como culpable del concurso de una entidad ${ }^{\mathrm{I}}$, indicando como personas afectadas por la calificación a los miembros de la comisión ejecutiva del consejo de administración y por la concurrencia de los siguientes supuestos generadores de culpabilidad:

\footnotetext{
${ }^{\mathrm{I}}$ Ley 22/2003, de 9 de julio, Concursal (en adelante LC).
}

La calificación del concurso persigue sancionar civilmente las conductas del deudor concursado, de sus representantes legales, de sus administradores o liquidadores e incluso de terceros que hubieran provocado o agravado el estado de la insolvencia. La calificación del concurso es totalmente independiente de las actuaciones penales que procedan por comportamientos del deudor que pudieran ser constitutivos de delito.

La sección de calificación no se forma en todos los concursos de acreedores, sino que depende, fundamentalmente, de la solución que se adopte en el mismo. El concurso deberá ser necesariamente calificado si se abre la fase de liquidación.

En cambio, si la solución es el convenio, sólo se formará la sección de calificación cuando se establezca una quita superior a un tercio de los créditos o una espera superior a tres años (art. I63.ILC).

El concurso de acreedores se calificará como fortuito o como culpable (art. I63.2 LC). La calificación del concurso como culpable tiene importantes efectos en el concurso.

El concurso se calificará como culpable cuando en la generación o agravación del estado de insolvencia hubiere mediado dolo o culpa grave del deudor o de sus representantes legales o de sus administradores o liquidadores.

El concurso será calificado, en todo caso, como culpable cuando concurra cualquiera de los siguientes supuestos (art. I64.2 LC):

- Incumplimiento sustancial del deber de contabilidad del deudor, incluyendo la doble contabilidad y la comisión de irregularidades relevantes para la comprensión de su situación patrimonial o financiera.

- Inexactitud grave o falsedad en los documentos acompañados o presentados en el concurso.

- Apertura de oficio de la liquidación por incumplimiento del convenio imputable al concursado.

- Alzamiento de bienes en perjuicio de los acreedores o realización de actos que obstaculicen o impidan la eficacia de un embargo.

- Salida fraudulenta de bienes o derechos del patrimonio del deudor en los dos años anteriores a la apertura del concurso.

- Realización antes del concurso de cualquier acto jurídico de simulación de una situación patrimonial ficticia.

- El concurso será también calificado como culpable, salvo prueba en contrario, cuando el deudor o, en su caso, sus representantes legales, administradores o liquidadores (art. I65 LC):

- Incumplan el deber de solicitar el concurso.

- Incumplan el deber de colaborar con el juez del concurso y con la administración concursal, no faciliten la información necesaria o conveniente para el interés del concurso o no hubiesen asistido a la junta de acreedores.

- No formulen cuentas anuales, las sometan a auditoría o las depositen en el Registro Mercantil, respecto de alguno de los tres años anteriores a la declaración de concurso.

Tendrán la consideración de cómplices las personas que, con dolo o culpa grave, hubieran cooperado con el deudor o, si los tuviere, con sus representantes legales y, en caso de persona jurídica, con sus administradores o liquidadores o con sus apoderados generales, a la realización de cualquier acto que haya fundado la calificación del concurso como culpable (art. I66 LC).

La calificación del concurso como culpable produce importantes efectos (art. I72.2 LC):

- La determinación de las personas afectadas por la calificación y, en su caso, la de las declaradas cómplices.

- La inhabilitación de las personas afectadas por la calificación para administrar bienes ajenos durante un período de dos a quince años, así como para representar o administrar a cualquier persona durante el mismo período.

- La pérdida de cualquier derecho que las personas afectadas por la calificación o las declarados cómplices tuvieran como acreedores en el concurso, así como, en su caso, la devolución de los bienes o derechos que hubieran obtenido indebidamente y la indemnización de los daños y perjuicios causados.

Además, si la sección de calificación se hubiera abierto como consecuencia de la apertura de la fase de liquidación, la sentencia podrá condenar a administradores y liquidadores, de hecho o de derecho, y a quienes hubieren tenido esa condición en los dos años anteriores a la apertura del concurso, a pagar a los acreedores concursales, total o parcialmente, el importe de sus créditos que no reciban en la liquidación. Es la llamada responsabilidad concursal. Cfr. Montón Redondo, Montón García: El Nuevo Proceso Concursal, Tirant lo Blanch, Valencia, 2005. Aznar Giner, Eduardo: El procedimiento de declaración del concurso necesario del deudor. Doctrina, jurisprudencia $y$ formularios, Tirant Lo Blanch, Valencia, $2^{\circ}$ edición, 20I2. Villate Menadas, Salvador: Elementos de Derecho Concursal, Tirant lo Blanch, Valencia, 20II. 
a) irregularidades contables graves ${ }^{2}$, por remisión a las observaciones expuestas en los informes de auditoria;

b) inexactitud grave de documentos aportados en la solicitud ${ }^{3}$ al no estar actualizado a ese momento el inventario y al lista de acreedores, limitándose las pretensiones interesadas a la inhabilitación por un periodo de dos años y pérdida de derechos que pudieran ostentar como acreedores;

c) retraso en la solicitud de concurso que agrava la insolvencia ${ }^{4}$, al estar incursa en insolvencia como lo puede revelar su fondo de maniobra negativo, las deudas significativas con empleados, AEAT y Tesorería General Seguridad Social y la concurrencia de causa de disolución societaria; demora que ha agravado la insolvencia.

\section{Delimitación del objeto}

Varias consideraciones previas procede hacer para delimitar el objeto procesal y configurar el planteamiento aplicado por los tribunales jurisdiccionales mercantiles que atienden, entre otros, y como no puede ser de otra manera, a los planteamientos doctrinales delimitados en la materia.

La primera es que las alegaciones fácticas y pretensiones de las partes configuran el alcance del pronunciamiento judicial, sin que pueda el Juzgador apreciar ex oficio supuestos de culpabilidad cuyo sustrato fáctico no haya sido debatido, o fijar consecuencias jurídicas no invocados ni para sujetos distintos a los solicitados en el momento procesal oportuno, por exigencia del principio de defensa y de un proceso con todas las garantías ${ }^{5}$, entre los que se encuentran el de alegación y prueba, precisando la sentencia de calificación una previa petición fundada, pues no hay que perder de vista que la Ley de Enjuiciamiento Civil es de aplicación supletoria en el proceso concursal, y por tanto, el principio esencial de rogación y dispositivo ${ }^{6}$, siendo la substanciación de los hechos en la norma correspondiente función judicial no vinculada a la que realicen las partes -iura novit curia- ${ }^{7}$.

Por tanto, de una parte, desde el punto de vista subjetivo, no puede enjuiciarse el comportamiento activo $u$ omisivo de miembros del consejo de administración que no han sido demandados. De otra, desde el punto de vista objetivo, las referencias de algunas personas afectadas a supuestos de calificación no invocados deben ser entendidas por superfluas y prescindibles.

Luego, es baladí, cualquier planteamiento de parte en un proceso, que mantenga que la concursada no es una sociedad mercantil sino deportiva, como si se trataran de categorías incompatibles, en abierta contradicción con nuestro derecho positivo constituido

\footnotetext{
${ }^{2}$ Cfr. art I64.2.I LC.

${ }^{3}$ Cfr. art.I64.2.2 LC.

${ }^{4}$ Cfr. art i64.I y i65.I LC.

${ }^{5}$ Cfr. art. 24 CE.

${ }^{6}$ Cfr. art. 2I8 LEC

${ }^{7}$ Así se deduce de las sentencias del TS de 22 de abril de 20 Io y I de abril de 2014 y sentencia de la AP de Murcia de 3I de julio de 2007 y 30 de julio de 2009, y AP de Alicante de I3 de enero de 2009 y las más recientes de 30 de marzo de 2012 y 25 de mayo de 2012.
} 
por el Real Decreto I251/i999, de I6 de julio, sobre sociedades anónimas deportivas según el cual Los clubes, o sus equipos profesionales, que participen en competiciones deportivas oficiales de carácter profesional y ámbito estatal deberán ostentar la forma de sociedad anónima deportiva en los términos y en los casos establecidos en la Ley 10/1990, de 15 de octubre, del Deporte, las disposiciones transitorias del Real Decreto 1084/1991, de 5 de julio, $y$ en el presente Real Decreto, siendo su objeto social la participación en competiciones deportivas de carácter profesional $\gamma$, en su caso, la promoción y el desarrollo de actividades deportivas, así como otras actividades relacionadas o derivadas de dicha practica ${ }^{8}$, sujetas, con las especialidades que prevé la normativa sectorial, a las mismas exigencias que las demás sociedades anónimas previstas en la Ley de Sociedades de Capital (en adelante LSC), antes TRLSA, que por definición, cualquiera que sea su objeto, tendrá carácter mercantil ${ }^{10}$.

La búsqueda del éxito deportivo no habilita a sus administradores a actuar al margen de la diligencia de un ordenado empresario. Tampoco alteraría esa conclusión el que el socio de referencia fuera público, acompañado de otras entidades con importante vinculo con el sector público.

No existe base legal que justifique el deber de guiar el pronunciamiento judicial concurrente para enjuiciar de manera distinta la sección sexta del concurso de una sociedad anónima deportiva del que es socio mayoritario un organismo local que la de otra sociedad anónima, sin que nos encontremos ante una asociación benéfica u ONG dedicada altruistamente a la promoción y el desarrollo de la actividad deportiva de base, en tanto en cuanto, atendemos a unos hechos enjuiciados que se corresponden a los de una sociedad que no solo tiene por objeto la promoción y el desarrollo del deporte, sino la participación en competiciones deportivas de carácter profesional, que manejaba un presupuesto de varios millones de euros.

Otra cosa es que siendo cierto que el estándar de comportamiento exigible al administrador de una sociedad ha de concretarse en función de la actividad de la misma y de las circunstancias en que se encuentre habrá que ponderar si la actuación de esos poderes públicos en la marcha de la SAD tiene, y en que medida, transcendencia a la hora de valorar el juicio de imputación subjetiva respecto de las personas afectadas ${ }^{\mathrm{II}}$.

Por su parte, el sistema de calificación concursal diseñado en la sección sexta no debe ser confundido con la normativa societaria en materia de responsabilidad de administradores societarios, especialmente por concurrir causa de disolución, ni el estado de insolvencia y la situación de pérdidas que reducen el patrimonio neto de la sociedad por debajo de la mitad del capital social, que es causa de disolución societaria ${ }^{\mathrm{i}}$.

\footnotetext{
${ }^{8}$ Cfr. arts. I y 2 Real Decreto I25I/I999, de I6 de julio, sobre sociedades anónimas deportivas.

${ }^{9}$ Real Decreto Legislativo I/20Io, de 2 de julio, por el que se aprueba el texto refundido de la Ley de Sociedades de Capital.

${ }^{\text {Io }}$ Cfr. art 2 LSC.

${ }^{\text {II }}$ Cfr. La sentencia del TS de 24 de mayo de 2013.

${ }^{12}$ Tal y como dice la sentencia del TS de I5 de octubre de 20I3, y ratifica en sede de calificación la sentencia del TS I abril 20I4 según la cual en la Ley Concursal la insolvencia no se identifica con el desbalance o las perdidas agravadas.
} 
Es posible que el patrimonio contable sea inferior a la mitad del capital social, incluso que el activo sea inferior al pasivo y, sin embargo, el deudor pueda cumplir regularmente con sus obligaciones, pues obtenga financiación.

Y, al contrario, el activo puede ser superior al pasivo pero que la deudora carezca de liquidez (por ejemplo, por ser el activo ser liquidable a muy largo plazo y no obtener financiación) lo que determinaría la imposibilidad de cumplimiento regular de las obligaciones en un determinado momento y, consecuentemente, la insolvencia actual. Por ello aunque con frecuencia se solapen, insolvencia y desbalance patrimonial no son equivalentes, lo determinante para apreciar si ha concurrido el supuesto de hecho del art. I65.I LC es la insolvencia, no el desbalance o la concurrencia de la causa legal de disolución por perdidas agravadas. En consecuencia, el esfuerzo en discutir si hay o no causa de disolución es en buena parte baldío.

En sede concursal los hechos deben ser analizados desde la óptica del art i64.I y su complementario art I65, o si tienen encaje en alguna de las hipótesis del art I64.2 LC, atendida la jurisprudencia del Tribunal Supremo, según la cual Ley 22/2003 sigue dos criterios para describir la causa de que el concurso se califique como culpable:

i. los casos previstos en el apartado 2 del articulo i64, en los que «la calificación es ajena a la producción del resultado contemplado en el apartado i del mismo articulo, ya que está condicionada a la ejecución por el sujeto agente de alguna de las conductas descritas en la propia norma [...], de modo que la ejecución de las conductas, positivas o negativas, que se describen en los seis ordinales de la norma, determina aquella calificación por si sola, esto es, aunque no haya generado o agravado el estado de insolvencia, por lo que, recurriendo a los conceptos tradicionales, puede decirse que el legislador describió en esta norma unos tipos de simple actividad» ${ }^{\mathrm{I3}}$.

ii. los supuestos del art I64.I y art. I65, indica que el articulo I65 no contiene un tercer criterio respecto de los dos del articulo I 64 - apartados i y 2 -, sino que es una norma complementaria de la del articulo I64, apartado I, viniendo la reciente sentencia de I abril de 20I4, al tratar de un supuesto de infracción del deber de solicitar la declaración de concurso a reseñar que el artículo i 65 de la Ley Concursal es una norma complementaria de la del articulo i64.I. Contiene efectivamente una concreción de lo que puede constituir una conducta gravemente culpable con incidencia causal en la generación o agravación de la insolvencia, y establece una presunción «iuris tantum» en caso de concurrencia de la conducta descrita, el incumplimiento del deber legal de solicitar el concurso, que se extiende tanto al dolo o culpa grave como a su incidencia causal en la insolvencia, que al ser reiterada en sentencia de 3 de julio 20I4, ha provocado una modificación de la exegesis mantenida hasta ese momento por la mayoría de órganos judiciales sobre el alcance del art I65, de manera que, tras esta doctrina jurisprudencial, al menos en lo relativo a la demora en la solicitud de concurso, si no se desvirtúa esa presunción, procede la declaración de concurso culpable, sin precisar esfuerzo probatorio adicional por la actora referente a si a ese comportamiento omisivo se puede ligar causalmente el agravamiento patrimonial de la

${ }^{13}$ Cfr. la sentencia del TS de I6 de enero de 20I2, con cita de la sentencia 644/20II, de 6 de octubre. 
concursada, pues les corresponderá a los demandados probar que, no obstante la demora en la solicitud, ello no ha causado o agravado la insolvencia ${ }^{\mathrm{I}}$.

Pero es más, si a ello le unimos que no exige responsabilidad por déficit, al no entrar en juego el art I72bis LC por no derivarse la formación de la sección sexta de la apertura de liquidación sino de la aprobación de un convenio gravoso, el debate sobre la cuantificador exacta de la agravación de la insolvencia no es tan esencial, pues, en su caso, lo relevante -si hay retardo - es la prueba de que no ha habido tal agravación.

\section{Supuesto de irregularidad contable}

Conforme al art. I64.2. $\mathrm{I}^{\circ}$ el concurso se califica como culpable cuando el deudor legalmente obligado a la llevanza de contabilidad incumpliera sustancialmente esta obligación, llevara doble contabilidad o hubiera cometido irregularidad relevante para la comprensión de su situación patrimonial o financiera en la que llevara.

De las tres hipótesis legales si atendemos en particular a la que presupone la existencia de una irregularidad contable clara, de acuerdo con las normas de contabilidad, y que además sea relevante en cuanto impida la comprensión cabal de la situación patrimonial o financiera de la sociedad ${ }^{15}$, definiéndose por la AP de Alicante el concepto de irregularidad relevante a partir de los siguientes elementos:

a) material: una información o una falta de información derivada de la contabilidad del deudor que no se corresponde con la realidad de una operación económica;

b) cuantitativo: esa discordancia entre la contabilidad y la realidad económica debe traducirse en unas diferencias económicas importantes, por lo que se excluirán las diferencias de escasa cuantía atendiendo al volumen del conjunto de operaciones del concursado;

c) cualitativo: debe afectar a elementos determinantes para conocer la verdadera situación patrimonial y financiera del concursado, por lo que se excluirán las irregularidades que no alteran de forma determinante la información sobre la verdadera situación patrimonial y financiera;

d) subjetivo: debe revelar la irregularidad cierta intencionalidad o el incumplimiento de las mas elementales reglas de la diligencia exigible al concursado $^{16}$, sin que quepa excusar dichas irregularidades en que la llevanza de la contabilidad no era el cometido del afectado en la sociedad, o que estaba encomendada a un profesional, pues el nombramiento como administrador no es meramente formal, sino que conlleva una serie de obligaciones, entre ellas - art 25 CCo- las de la llevanza y formulación de la contabilidad ${ }^{17}$, pero sin ser bastante las afirmaciones abstractas y genéricas sino que debe concretarse en que consiste

\footnotetext{
${ }^{\text {I4 }}$ Cfr. la sentencia del TS 6I4/20II, de I7 de noviembre y la sentencia de la AP de Barcelona de diciembre de 2014 .

${ }^{15}$ Cfr. la sentencia de la AP de Barcelona de ig de marzo de 2007.

${ }^{16}$ Cfr. la sentencia del TS de 30 de junio de 2011 .

${ }^{17}$ Cfr. las sentencias de AP de Córdoba de 23 de enero de 2013 y de I 8 de abril de 2012.
} 
la irregularidad contable, indicando la norma o principio contable vulnerado, y su relevancia, cualitativa y/o cuantitativa; carga que le corresponde a la parte actora ${ }^{18}$.

Si en la exposición de la Administración Concursal se remite a las incertidumbres, limitaciones y salvedades señaladas por los auditores en sus informes de auditoria concluyendo con la opinión de que las cuentas anuales muestran la imagen del patrimonio y situación financiera, siendo lo relevante comprobar si esos hechos expuestos revelan irregularidades contables por implicar la constatación registral - o su falta - de magnitudes económicas de manera indebida, precisamente, las auditorias externas y de cuya imparcialidad y rigor no debe ofrecer duda, atendidas las aclaraciones y explicaciones realizadas, y si lo que muestran es que la inclusión - o su falta- de determinadas partidas o conceptos no aparece justificada o soportada documentalmente, pues no hay prueba contundente que cuestione este dato en esos particulares (al margen de opiniones sobre los fondos de maniobra, o la concurrencia de causa de disolución, que si son controvertidas en los escritos de oposición) la conclusión es que hay que estimar indebidamente registrados esos conceptos o partidas por ausencia de causa que lo soporte, a salvo que dicha causa efectivamente conste y así se acredite.

La apreciación del supuesto art I64.2.I LC no se agota en la irregularidad contable entendida como infracción de los principios y normas de contabilidad generalmente aceptados previstos en el art 38 CCo y Plan General de Contabilidad aprobado por RD I514/2007, de I6 de Noviembre, que en su Primera Parte (Marco conceptual de la contabilidad) los define, pues es preciso que sea relevante en los términos antes expuesto, sirviendo de punto de partida, entre otros, los parámetros de la RICAC de I4 de Junio de I999, por la que se publica la Norma Técnica de Auditoria sobre el concepto de «Importancia Relativa», que las Normas Técnicas de Auditoria sobre ejecución del trabajo definen como La magnitud o naturaleza de un error (incluyendo una omisión) en la información financiera que, bien individualmente o en su conjunto, y a la luz de las circunstancias que le rodean, hace probable que el juicio de una persona razonable, que confía en la información, se hubiera visto influenciado o su decisión afectada como consecuencia del error u omisión, y que se fija ponderando los aspectos cualitativos y cuantitativos de la incidencia a la hora de mostrar la imagen fiel del patrimonio y su situación financiera.

En definitiva, el art I64.2. I LC no se limita a las acciones u omisiones dolosas que sean relevantes para la comprensión de la situación patrimonial o financiera, pues;

(i) la norma concursal no lo prevé; (ii) no concuerda con la clausula general el art I64.I que comprende no solo actuaciones dolosas sino también la culpa grave y (iii) tampoco casa con la propia naturaleza de tipo de actividad del art I64.2.I -en palabras del TS- que exime de probar el dolo o culpa grave generador de insolvencia, pues significaría trasladar la dificultad de esa actividad probatoria (que el legislador quiere eximir) a la prueba del hecho base (la irregularidad como comportamiento intencionado).

Este planteamiento es el consagrado por el TS en sentencia de I6 de Enero de 20I2, con descarte de la tesis contable, diciendo que ... por razón de la trascendencia que se atribuye a la función informativa de las declaraciones de conocimiento en que consisten las cuentas anuales, la distinción entre error e irregularidad en que, por razón de la intencionalidad, se basa el

\footnotetext{
${ }^{18}$ Cfr. las sentencias de la AP de Pontevedra de 2 mayo de 2013 y SAP de Valencia de I4 diciembre de $201 \mathrm{I}$.
} 
primero de los motivos del recurso de casación, carece de significación para la comisión del comportamiento que se describe en la norma del ordinal primero del apartado 1 del articulo 164 de la Ley 22/2.003, de 9 de julio, dado que la realización del tipo que en ella se describe no exige que el sujeto agente tenga consciencia del alcance $y$ significación jurídica de su acción u omisión ni que el resultado del comportamiento sea querido por el. Lo que no significa que las consecuencias de la calificación deban ser necesariamente ajenas al reproche que merecen las manifestaciones culposas o dolosas de la irregularidad y que es la seguida por la llamada jurisprudencia menor ${ }^{\mathrm{r}}$.

Luego la irregularidad contable, y su alcance, no desaparece por el hecho de que el informe de auditoría exponga limitaciones, salvedades e incertidumbres, y su lectura conjunta permita apreciarlas, y valorar así la situación patrimonial y financiera de la sociedad. Y ello por varias razones:

i) no puede presumirse que el examen conjunto de las cuentas anuales con la auditoria permita a un usuario medio de esa información (que no es experto y al que no es exigible conocimientos contables suficientes o la obligación de examinar debidamente toda la contabilidad ${ }^{20}$, alcanzar a comprender la verdadera situación patrimonial o financiera de la concursada;

ii) la irregularidad no desaparece aunque se consiga desentrañar con la auditoria cual era la verdadera situación patrimonial o financiera de la sociedad, como se aprecia si analizamos la jurisprudencia societaria en materia de impugnación de acuerdos sociales;

iii) la auditoria no puede tener efecto sanatorio de las irregularidades contenidas en las cuentas anuales, dado que lo que forman una unidad son los documentos previstos en el art $34 \mathrm{CCo}$, no la auditoria, que además, no procede de la sociedad sino de un tercero independiente, $\mathrm{y}$

iv) si los administradores después de presentado el informe de auditoria no deciden alterar la cuentas anuales (como prevé el art 270LSC) lo que significa es que frente a terceros consideran que la imagen patrimonial es la reflejada en las cuentas, sin las verificaciones del auditor, por lo que, en lógica consecuencia, deberán responder si después las cuentas anuales no reflejan la realidad patrimonial por ser acertadas las observaciones del auditor.

\section{Inexactitud grave en los documentos acompañados a la solicitud de declaración de concurso}

Se trata del supuesto legal previsto en el apartado 2 del art $\mathrm{I} 64.2 \mathrm{LC}$, generalmente aceptado que para su apreciación no basta cualquier inexactitud documental sino que ha de limitarse a aquella que (a) no haya sido ya objeto de valoración por aplicación de precepto preferente (vgra. las cuentas anuales acompañadas por aplicación del art I64.2.I LC), (b) tenga una trascendencia informativa importante, y (c) revele un comportamiento del deudor merecedor de reproche a titulo de culpa grave (pues el dolo parece reservarse a la hipótesis de presentación de documentos falsos), de manera que han de quedar excluidos aquellos

${ }^{19}$ Cfr. entre otras sentencias de la AP de Las Palmas de Gran Canaria, de 24 julio de 2013 o AP de Córdoba, de 9 julio de 2014 .

${ }^{20}$ Cfr. la sentencia de la AP de Salamanca de 28 de Diciembre de $20 \mathrm{2} 2$. 
defectos documentales que apreciados en su conjunto no impidan obtener la información que el deudor debe facilitar, y que el legislador de esta manera pretende garantizar, a los efectos de valorar si la conducta del deudor común tiene incidencia con el origen o agravación del concurso.

Luego, se trata, de evitar una interpretación extensiva, por los importantes efectos que conlleva (la inexcusable declaración de culpabilidad al no permitir prueba que la destruya) que no sea adecua a la finalidad de la norma y a su interpretación sistemática, si lo ponemos en relación con el articulo I64 .I. y i65.2 que releva a la categoría de presunción iuris tantum la no facilitación de información necesaria o conveniente para el interés del concurso.

Así, la sentencia de la AP de Barcelona de I6 de julio de 2009 establece que la inexactitud supone falta de adecuación a la realidad de la información contenida en dicha documentación, siendo el documento autentico y valido. Como hemos aclarado en otras ocasiones (Sentencia de 30 de diciembre de 2008), esta inexactitud debe ser grave, y lo será cuando se refiera a una información relevante para el concurso, en concreto para alguna de sus operaciones sobre la masa activa o pasiva, para la calificación o para la aprobación del convenio. La sentencia aprecia que han existido inexactitudes graves en la documentación aportada con la solicitud de concurso sobre la base de los siguientes hechos, previamente declarados probados:

i) los bienes relacionados en el inventario aportado por la concursada, en cumplimiento del requerimiento del que fue objeto en el auto de declaración de concurso (art. 21 LC ), y que consta en este incidente (...), no fueron encontrados por la administración concursal, por lo que no pudieron ser incluidos en el inventario;

ii) en la lista de acreedores aportada por la concursada aparecían créditos por un importe de 1.540.806,28 euros, $y$ en la lista definitiva elaborada por la administración concursal los créditos concursales ascendían a un importe total de 1.875.285,55 euros. Así como la diferencia del pasivo no es del todo relevante, pues parte de ella puede ser debida a diferencias respecto de su existencia, sin embargo si es relevante, a los efectos de poder apreciar la causa de calificación del art. 164.2.20 LC, que la concursada hubiera suministrado en mayo de 2005 una relación de bienes, existencias e inmovilizado que no existía, pues, como reconoció mas tarde, muchos de ellos los había enajenado entre los meses de agosto y octubre de 2004. Esta inexactitud es muy grave, pues afecta al activo que debía formar parte de la masa activa del concurso, y no se refiere a un bien sin relevancia económica, sino a los que gozaban de valor económico, como pone de relieve la administradora concursal en su informe $y$ no ha sido contradicho... De igual modo, la SAP de Madrid de 4/12/2009 dice que recayendo la inexactitud sobre el inventario de bienes $y$ derechos esta solo podrá calificarse de grave cuando tergiverse de manera importante o sustancial la imagen del activo del deudor.

\section{El retraso en la solicitud de concurso}

El articulo I65 LC presume la existencia de dolo o culpa grave, salvo prueba en contrario, cuando el deudor o, en su caso, sus representantes legales, administradores o liquidadores, hubiere incumplido el deber de solicitar la declaración de concurso; norma que remite al articulo 5, que establece un plazo de dos meses para solicitar el concurso desde la fecha en que el deudor hubiera conocido o debido conocer su estado de insolvencia, que añade que, salvo prueba en contrario, se presumirá que el deudor ha 
conocido su estado de insolvencia cuando haya acaecido alguno de los hechos que pueden servir de fundamento a una solicitud de concurso necesario conforme al apartado 4 del articulo 2, es decir, los conocidos como hechos reveladores de insolvencia, si se considera que existe una demora en la solicitud de concurso presentada y se estaba en insolvencia que se define en el articulo 2.2 LC como el estado del deudor que no puede cumplir regularmente las obligaciones exigibles, que se desprende, salvo prueba en contrario, con la acreditación de la concurrencia de un hecho revelador de insolvencia (art. I8 LC), que la doctrina científica los califica como supuestos de insolvencia cualificada por evidenciar un estado económico y financiero particularmente grave.

Como estado precisa que se trate de un situación de hecho de cierta permanencia, que implica una impotencia patrimonial de atender sus obligaciones exigibles, por lo que no desaparece si puede atender unas y otras no, pero en todo caso siempre que sean exigibles, de manera que si no lo son no son computables para su apreciación, sin que valga tampoco cualquier cumplimiento, pues debe ser regular, es decir, por los medios normales. Por otra parte, la amplitud del concepto legal implica que sea compatible con la existencia de un balance saneado si, simultáneamente, el deudor carece de liquidez necesaria para atender esas obligaciones exigibles ${ }^{21}$. Es un error equiparar el estado de insolvencia con la situación de pérdidas cualificadas que reducen el patrimonio neto de la sociedad por debajo de la mitad del capital social ${ }^{22}$.

Ahora bien, hay un incumplimiento generalizado de obligaciones especialmente cualificadas, que se prolonga mucho más allá de los tres meses que el legislador considera como revelador de supuesto de insolvencia cualificada en el art $2.44^{\circ}$ LC. Por tanto, lo que muestra ese dato es que se tenía una manifiesta impotencia patrimonial para atender de manera regular sus obligaciones exigibles, o sea, que estaba en insolvencia actual. Cierto es que si se solicita aplazar el pago de esas obligaciones, pero esa petición de aplazamiento solo se concede mucho después, sin que la sola petición de aplazamiento desvirtué lo dicho. La exigibilidad, según la doctrina administrativista, hace referencia al momento en que se ha liquidado la obligación - o debe autoliquidarse- y debe realizarse el ingreso de la deuda, según se deduce del arts. 2I y 62 de la Ley 58/2003, General Tributaria (en adelante LGT), sin que a ello afecte la solicitud de aplazamiento/fraccionamiento prevista en el art 65.

Tal solicitud en periodo voluntario lo que podrá impedir es el inicio del periodo ejecutivo (y por ende, los recargos del periodo ejecutivo, art 28 LGT), pero no el devengo del interés de demora, ni siquiera la ejecutividad de la deuda tributaria, pues la Administración tributaria podrá iniciar o, en su caso, continuar el procedimiento de apremio durante la tramitación del aplazamiento o fraccionamiento, no obstante, el deber de suspender las actuaciones de enajenación de los bienes embargados hasta la notificación de la resolución denegatoria del aplazamiento o fraccionamiento.

De igual manera el Reglamento General de Recaudación, en sus artículos 5I, 52, 53 y 54 establecen intereses de demora desde el día siguiente al del vencimiento del plazo de ingreso en periodo voluntario, y si ello es así es porque se considera que desde ese momento es exigible la deuda, de manera que su pago posterior debe compensarse al acreedor satisfaciendo los consiguientes interés por demora.

\footnotetext{
${ }^{21}$ Cfr. la sentencia de la AP de Madrid de I8 noviembre de 2008.

${ }^{22}$ Cfr. las sentencias del TS de I5 octubre de 2013 y de I de abril 2014.
} 
Podemos encontrar pronunciamientos judiciales, que llegan a afirmar que la solicitud de aplazamiento es un hecho inequivocamente significativo del conocimiento de la situación de insolvencia ${ }^{23}$.

Afirmada la demora en la solicitud de concurso, la prueba de que ello no ha implicado una agravación de la insolvencia corresponde a los demandados, según la reciente doctrina jurisprudencial de la que es buena muestra la SAP de Barcelona de 20 octubre 2014 que precisamente ante un impago de deudas fiscales dice ...la sentencia fija la situación de insolvencia a 31 de diciembre de 2009, momento en que, incuestionablemente, ya se había producido el hecho revelador de la insolvencia contemplado en el apartado cuarto del articulo 2.40 de la Ley Concursal. A partir de ahí, a la concursada incumbía la carga de acreditar que, a pesar de ello, la insolvencia concursal, entendida como la imposibilidad de cumplir regularmente con las obligaciones exigibles ( articulo 2 de la Ley Concursal), no concurría en aquel momento y que la demora en la solicitud de concurso no agravó la insolvencia. Prueba que no consta, limitándose, en general, la concursada y afectados a cuestionar la agravación de la insolvencia imputada por la AC (mas de 6 millones de euros), y en concreto, que las magnitudes consideradas por esta (asumidas por MF) no son homogéneas.

En consecuencia, el retraso en la solicitud de concurso permite calificar también el concurso como culpable ex art I64.I en relación con el art I65.I según la actual doctrina jurisprudencial, que completa el ordenamiento jurídico, y que por seguridad jurídica se asume $^{24}$.

La LC impone el comportamiento a seguir por el deudor en esa situación de insolvencia (solicitar el concurso ${ }^{25}$ ), y si se aparta del mismo en la confianza de revertir su situación económica, pero después no se produce ese resultado, debe asumir sus consecuencias, o dicho de otra manera, el riesgo de agravamiento de la insolvencia se traslada al deudor, al no ajustar su actuación al estándar legal ${ }^{26}$.

La opción personal por no cumplir con la ley si confiar en uno o varios negocios como cauce de restauración financiera, al margen de los cauces legales de refinanciación, constituye la voluntad que genera en el caso la agravación del concurso pues aun en la hipótesis de la ajenidad del fracaso comercial a la actuación de la mercantil concursada, la voluntariedad estuvo en no actuar conforme a la ley, hay un momento determinado en que declararse en concurso era obligatorio para la mercantil. No lo hizo y se vio abocado a un estado concursal necesario en un momento en el que, con aquella conducta, el pasivo había crecido en perjuicio de sus acreedores que veían disminuidas sus posibilidades de satisfacción de sus créditos. En todo caso la búsqueda del éxito deportivo no puede servir de eximente para no ajustar el comportamiento al estándar de diligencia legalmente exigible ${ }^{27}$.

${ }^{23}$ Cfr. la Sentencia de la AP de Burgos de iو de febrero de 20 Io y la sentencia de la AP de Asturias de 20 de diciembre de 2010 .

${ }^{24}$ Cfr. art I.6 CC y 9 CE.

${ }^{25}$ Cfr. art. 5 LC.

${ }^{26}$ Esta idea subyace en la sentencia de la AP de Alicante de II septiembre de 2014 en la que se dice: Era opción del empresario cumplir con su obligación de promover el concurso transcurridos mas de tres meses desde impagos fiscales y a la Seguridad Social o actuar en el marco del aleas del futuro de negocios en la confianza de su triunfo $y$ solventar el panorama económico que impetraba la promoción actual del concurso

${ }^{27}$ Cfr. la sentencia del TS de 24 mayo de 2013. 


\section{Elementos subjetivos}

La declaración del concurso como culpable por concurrencia del supuesto del art I64.2.I y art I64.I en relación con art I65.I LC implica analizar si los demandados deben ser condenados como personas afectadas por la calificación, condición que el art I72.2 LC, en el caso de personas jurídicas, reserva a sus administradores o liquidadores, de hecho o de derecho, apoderados generales, y quienes hubieren tenido esa condición en los dos años anteriores a la declaración del concurso.

Los administradores de la sociedad de capital podrán ser personas físicas o jurídicas (art 2I2 LSC y el precedente art I25 LSA y art I43 RRM), y en este último caso, será necesario que esta designe a una sola persona natural para el ejercicio permanente de las funciones propias del cargo (art 2I2 bis LSC desde la Ley 25/20II) que recoge lo indicado en el art I43 RRM que venia a colmar esa laguna legal.

Presupuesto necesario para ello es ostentar la condición de administradores, y esta la ostentan las personas jurídicas, que no solo la literalidad de los preceptos conducen a esta conclusión, sino que hasta la Ley 3I/20I4, a la persona física designada solo le era exigible legalmente el deber de sigilo (art 232.3 LSC, anterior art I27 quater LSA), lo cual era criticado por la doctrina, que echaba en falta la extensión de la responsabilidad del administrador a esta persona física, de manera que la mayoría de comentaristas consideraba, en sede societaria, que en la medida en que la persona física designada representante actuaba en nombre y por cuenta de otra (la persona jurídica administradora), la eficacia de lo actuado por el primero se imputa a la esfera jurídica de la segunda, o sea, a la persona jurídica administradora, que es la que podía ser demandada directamente por la sociedad, socio terceros por los daños causados por el representante, sin perjuicio de la acción de regreso contra este, siendo minoritarias las posturas que distinguían entre imputación de la conducta a la persona física (dado el carácter «personal» de la responsabilidad) y las consecuencias patrimoniales, repercutibles a la persona jurídica representada. Y ello al margen de acudir a la figura del levantamiento del velo si se acredita un uso fraudulento de la personalidad jurídica, o inclusive a la del administrador de hecho cuando en la actuación de la persona física concurran los requisitos que permiten aplica tal figura $^{28}$.

La reforma de la LSC operada por la Ley 3I/20I4 ahora si prevé esa extensión en el nuevo apartado 5 del art 236 según el cual la persona física designada para el ejercicio permanente de las funciones propias del cargo de administrador persona jurídica deberá reunir los requisitos legales establecidos para los administradores, estará sometida a los mismos deberes $y$ responderá solidariamente con la persona jurídica administrador, y entre ellos, como manifestación del deber de lealtad, el de Desempeñar sus funciones bajo el principio de responsabilidad personal con libertad de criterio o juicio e independencia respecto de instrucciones $y$ vinculaciones de terceros (art 228.e).

Por tanto, desde la entrada en vigor de esta Ley, se respeta la condición de administrador a la persona jurídica, pero se impone el mismo régimen de responsabilidad a la persona física designada para el ejercicio permanente de las funciones propias del cargo de administrador persona jurídica, sin que ello libere a esta última, al establecerse su

\footnotetext{
${ }^{28}$ Cfr. la sentencia de la AP de Madrid de I diciembre 2009.
} 
responsabilidad solidaria. Este cambio legal revela la insuficiencia del régimen legal anterior, de manera que en aquellos supuestos al no ser aplicable ratione tempore la Ley 3I/20I4, queda vedado cualquier atisbo que permita acudir a la misma para integrar el concepto de sujetos responsables y considerar, en sede de calificación concursal, como persona afectada ex art I72 LC a la persona física designada representante de la persona jurídica administradora, siendo esta la que ostenta esa condición, y por ende, la que deba soportar todas las consecuencias derivadas, sin que la previsión de la sanción civil de inhabilitación altere esa conclusión, pues se refiere a administrar patrimonios ajenos, no a su muerte civil ${ }^{29}$.

Por todo lo anterior, respecto de la demora en la solicitud de concurso, hay que partir de que la legitimación para solicitar la declaración de concurso, corresponde a los órganos de administración de las sociedades mercantiles deudoras (art. 3.I.II LC) ${ }^{30}$. Por tanto, si el Consejo de Administración tenía delegadas en la comisión ejecutiva todas las facultades -excepto las indelegables- la solicitud de concurso no precisaba intervención del Consejo de Administración y menos de la Junta General.

Ahora bien, si la sola delegación basta para eximir de responsabilidad al delegante, habiendo dicho la jurisprudencia en materia de responsabilidad societaria que ... no desaparece por el hecho de que el consejo de administración de la misma hubiera designado un consejero delegado ${ }^{31}$ pues los legitimados desde el punto de vista de la exigencia de responsabilidad son quienes ostentan esta condición, independientemente de que determinadas facultades del consejo de administración hayan sido delegadas en consejeros concretos, puesto que estos actúan por mandato de los administradores o como gestores de estos, y solo cabe eximir a aquellos de responsabilidad en el caso de que... prueben que, no habiendo intervenido en la adopción y ejecución del acuerdo lesivo, desconocían su existencia o, conociéndola, hicieron todo lo conveniente para evitar el daño o, al menos, se opusieron expresamente a aquel ${ }^{32}$.

Ciertamente, si hablamos del concurso de una sociedad deportiva en cuanto al componente deportivo, y siendo ...cierto que el estándar de comportamiento exigible al administrador de una sociedad ha de concretarse en función de la actividad de la misma $y$ de las circunstancias en que se encuentre y que el riesgo implícito en la gestión de una sociedad que actúa en un mercado tan difícil con el del fútbol de competición no puede ser calificada solo por sus

\footnotetext{
${ }^{29}$ La jurisprudencia menor representada entre otras por la sentencia de la AP de Barcelona de 20 octubre 2014 que, con cita de las precedentes sentencias de 26 de marzo de 2014 y i 6 de noviembre de 20 II, recuerda que la responsabilidad recae en el administrador persona jurídica y no en la persona física designada como representante, máxime cuando, como acontece en el presente caso, la persona física ha sido demandada (y condenada) como administrador de derecho...

30 En las Conclusiones del Primer Encuentro de Especialidad Mercantil (Valencia, 9 y ro de diciembre de 2004) han de aplicarse las reglas para la formación de voluntad por parte del órgano de administración de la sociedad: actuación conjunta de los administradores mancomunados, acuerdo adoptado en el consejo de administración (art. 140 y siguientes de la Ley de Sociedades Anónimas) o decisión adoptada por consejero delegado dentro del ámbito de las funciones objeto de delegación, actuación de cualquier administrador solidario. Una vez tomada la decisión por el órgano de administración, se formulara la solicitud ante el Juzgado conforme a las reglas que rijan la representación de la sociedad por el órgano de administración (por ejemplo, es posible que la decisión se adopte por el consejo de administración, por no estar delegada esa función, pero el poder especial a Procurador para presentar la solicitud se otorgue por el consejero delegado) dicho planteamiento ha sido asumida, entre otras, por la sentencia de la AP de Vizcaína, de 30 marzo 2009.

${ }^{31}$ Cfr. la sentencia del TS I4 de julio de 20 io.

${ }^{32}$ Cfr. la sentencia del TS I de diciembre de 2008.
} 
resultados, particularmente los deportivos, pues hay que reconocer, dentro del antes referido modelo, un cierto margen de discrecionalidad al administrador en su gestión ello no justifica cualquier comportamiento, descartándose como circunstancia exonerante la búsqueda del éxito deportivo (El acuciante deseo de obtener éxitos en el campeonato - con la contratación de nuevos futbolistas - no puede explicar las desviaciones presupuestarias, tanto mas si es notorio que los buenos resultados deportivos no son incompatibles con un diligente rigor en dicha materia) $)^{33}$.

En realidad, lo que viene a decir el TS en la sentencia de 24 de mayo 2013 (caso Real Sociedad) se inserta en la doctrina general según la cual la responsabilidad del administrador es una obligación de medios y no de resultado, puesto que el ejercicio de una actividad mercantil comporta un riesgo que, en las sociedades de capital, es asumido directamente por estas (art. I LSC) de manera que el administrador no tiene por que responder del éxito de su gestión Lo relevante en todo caso es que esa decisión empresarial se ajuste a los procedimientos establecidos en la ley y estatutos, sea ponderada en el sentido de haber atendido el deber de información exigible a todo empresario y que el interés que justifique su adopción sea el interés social y no otros particulares de los administradores o terceros. Idea consagrada en el nuevo artículo 226 rubricado «Protección de la discrecionalidad empresarial».

Así, podemos sostener;

i) la existencia de un administrador de hecho no exime de responsabilidad al de derecho, ya que la partícula «o» del art I64.I LC no ha de ser entendida en sentido excluyente, sino que debe interpretarse como posibilidad de abarcar tanto a uno como a otro.

ii) nos encontraríamos en todo caso ante dos administradores, de manera que responderá cada uno de ellos solidariamente, salvo que se acredite una participación distinta en el comportamiento infractor, valiendo por extensión analógica la previsión legal en materia de sociedades de capital que determina la responsabilidad del administrador de hecho, pero no lo hace con exclusión del de derecho.

La reforma legal de la LSC operada por la Ley 3I/20I4, prevé en el art. 236.3 es la extensión de la responsabilidad de los administradores a los administradores de hecho, por lo tanto sin excluir la de aquellos por la de estos, sino su coexistencia, también en el caso del administrador oculto que actúa como tal sirviéndose de instrucciones al administrador de derecho que actúa como «mero testaferro $u$ hombre de paja».

iii) su actuación es complemento necesario del comportamiento del administrador de hecho en su modalidad de administrador oculto, cooperando con este de manera activa y consciente, de manera que después no puede pretender eximirse de su actuación, por lo que debe asumir, solidariamente con aquel, las consecuencias derivadas de la gestión empresarial del administrador de facto; sin olvidar que la negligencia no solamente se predica por acción sino también por omisión, dejando la mercantil sin control, pues se responde tanto de actos propios como de los realizados por las personas designadas (culpa in eligiendo o in vigilando).

${ }^{33}$ Cfr. la sentencia del TS de 24 de mayo de 2013. 
iv) si en sede de responsabilidad societaria no es motivo de exculpación el acuerdo del supremo órgano de la sociedad, mucho menos lo puede ser la presencia de un tercero, y respecto del que el administrador de derecho formalmente es autónomo.

Este parecer es el acogido por la llamada jurisprudencia menor, y así la AP de Jaén de I3 abril de 2007 en supuesto de calificación concursal en el que se invocaba esta alegación indica que no es de recibo dado que «el cargo de administrador no es un cargo 'honorifico' ni un título formal sino que implica una serie de derechos y deberes de obligado cumplimiento», y de igual manera en un supuesto del art 48 LC el Auto de la AP de Tarragona de 2I febrero de 2006 frente a la invocación de que el demandado había asumido la administración formal de la concursada que evitaba la existencia de conducta dolosa o culposa, ensena que ello «implica todo lo contrario, pues si su condición de administrador fue puramente formal, ello supone una clara negligencia y le hace manifiestamente culpable de cualquier situación irregular que haya conducido a la situación de insolvencia, pues hace patente su voluntario incumplimiento de todos los deberes que afectan a un administrador, ya que es totalmente rechazable el cumplimiento de la mera formalidad con dejación de los deberes que tan trascendental cargo implica»; y aunque la Sentencia del TS de 4 de diciembre de 2012 se muestra cautelosa respecto de la coexistencia de administradores de hecho y de derecho, partiendo de la regla general de que responde de los danos derivados de la administración lesiva el administrador de derecho, también admite «la posible coexistencia de administradores de derecho puramente formales con otro $u$ otros de hecho, singularmente cuando se acredita que la designación formal tiene por objeto eludir la responsabilidad de quien realmente asume el control y gestión de la sociedad bajo la cobertura del apoderamiento...», por lo que se considera que es posible afirmar la responsabilidad de la persona que real y efectivamente ejerce las funciones de administrador de la sociedad, así como la del administrador/es de derecho, que figura/n como tal/es frente a terceros, y que de consuno actúan, al asumir este ultimo sin cuestionarse su bondad- las decisiones del primero, ejecutándolas personalmente cuando ello es preciso.

\section{Conclusiones}

I. Tal y como hemos señalado en la exposición en sede concursal los hechos deben ser analizados desde la óptica del art. I64.I y su complementario art. I65, y atendida la jurisprudencia del TS, según la cual Ley 22/2003 sigue dos criterios para describir la causa de que el concurso se califique como culpable: i.- los casos previstos en el apartado 2 del articulo I64, en los que «la calificación es ajena a la producción del resultado contemplado en el apartado I del mismo articulo, ya que está condicionada a la ejecución por el sujeto agente de alguna de las conductas descritas en la propia norma [...], de modo que la ejecución de las conductas, positivas o negativas, que se describen en los seis ordinales de la norma, determina aquella calificación por si sola, esto es, aunque no haya generado o agravado el estado de insolvencia, por lo que, recurriendo a los conceptos tradicionales, puede decirse que el legislador describió en esta norma unos tipos de simple actividad». ii.los supuestos del art. I64.I y art. I65, indica que el articulo I65 no contiene un tercer criterio respecto de los dos del art. $\mathrm{I}_{4}$ - apartados I y 2 -, sino que es una norma complementaria de la del articulo I64, apartado I, viniendo la reciente sentencia de I abril de 20I4, al tratar de un supuesto de infracción del deber de solicitar la declaración de 
concurso a reseñar que el art. I65 LC es una norma complementaria de la del articulo i64.I. Contiene efectivamente una concreción de lo que puede constituir una conducta gravemente culpable con incidencia causal en la generación o agravación de la insolvencia, y establece una presunción iuris tantum en caso de concurrencia de la conducta descrita, el incumplimiento del deber legal de solicitar el concurso, que se extiende tanto al dolo o culpa grave como a su incidencia causal en la insolvencia, que al ser reiterada en sentencia de 3 de julio 20I4, ha provocado una modificación de la exégesis mantenida hasta ese momento por la mayoría de órganos judiciales sobre el alcance del art. I65, de manera que, tras esta doctrina jurisprudencial, al menos en lo relativo a la demora en la solicitud de concurso, si no se desvirtúa esa presunción, procede la declaración de concurso culpable, sin precisar esfuerzo probatorio adicional por la actora referente a si a ese comportamiento omisivo se puede ligar causalmente el agravamiento patrimonial de la concursada, pues les corresponderá a los demandados probar que, no obstante la demora en la solicitud, ello no ha causado o agravado la insolvencia.

II. La existencia de una irregularidad contable clara, de acuerdo con las normas de contabilidad, y que además sea relevante en cuanto impida la comprensión cabal de la situación patrimonial o financiera de la sociedad, definiéndose por la AP de Alicante el concepto de irregularidad relevante a partir de los siguientes elementos: a) material: una información o una falta de información derivada de la contabilidad del deudor que no se corresponde con la realidad de una operación económica; b) cuantitativo: esa discordancia entre la contabilidad y la realidad económica debe traducirse en unas diferencias económicas importantes, por lo que se excluirán las diferencias de escasa cuantía atendiendo al volumen del conjunto de operaciones del concursado; c) cualitativo: debe afectar a elementos determinantes para conocer la verdadera situación patrimonial y financiera del concursado, por lo que se excluirán las irregularidades que no alteran de forma determinante la información sobre la verdadera situación patrimonial y financiera; d) subjetivo: debe revelar la irregularidad cierta intencionalidad o el incumplimiento de las mas elementales reglas de la diligencia exigible al concursado ${ }^{34}$, sin que quepa excusar dichas irregularidades en que la llevanza de la contabilidad no era el cometido del afectado en la sociedad, o que estaba encomendada a un profesional, pues el nombramiento como administrador no es meramente formal, sino que conlleva una serie de obligaciones, entre ellas - art. 25 CCo- las de la llevanza y formulación de la contabilidad, pero sin ser bastante las afirmaciones abstractas y genéricas sino que debe concretarse en que consiste la irregularidad contable, indicando la norma o principio contable vulnerado, y su relevancia, cualitativa y/o cuantitativa; carga que le corresponde a la parte actora.

III. En cuanto a la inexactitud de los documentos que acompañan a la solicitud de concurso hemos de constatar la sentencia de la AP de Barcelona de I6 de julio de 2009 establece que La inexactitud supone falta de adecuación a la realidad de la información contenida en dicha documentación, siendo el documento autentico y valido. Como hemos aclarado en otras ocasiones (Sentencia de 30 de diciembre de 2008), esta inexactitud debe ser grave, $y$ lo será cuando se refiera a una información relevante para el concurso, en concreto para alguna de sus operaciones sobre la masa activa o pasiva, para la calificación o para la aprobación del convenio. La sentencia aprecia que han existido inexactitudes graves en la documentación

${ }^{34}$ Cfr. la sentencia del TS de 30 de junio de 20 II. 
aportada con la solicitud de concurso sobre la base de los siguientes hechos, previamente declarados probados:

IV. En el retraso en la solicitud de concurso hay un incumplimiento generalizado de obligaciones especialmente cualificadas, que se prolonga mucho más allá de los tres meses que el legislador considera como revelador de supuesto de insolvencia cualificada en el art. $2.44^{\circ}$ LC. Por tanto, lo que muestra ese dato es que se tenía una manifiesta impotencia patrimonial para atender de manera regular sus obligaciones exigibles, o sea, que estaba en insolvencia actual. Cierto es que si se solicita aplazar el pago de esas obligaciones, pero esa petición de aplazamiento solo se concede mucho después, sin que la sola petición de aplazamiento desvirtué lo dicho. La exigibilidad, según la doctrina administrativista, hace referencia al momento en que se ha liquidado la obligación - o debe auto liquidarse- y debe realizarse el ingreso de la deuda, según se deduce del arts. 2I y 62 Ley 58/2003, LGT, sin que a ello afecte la solicitud de aplazamiento/fraccionamiento prevista en el art. 65 .

V. En relación al elemento subjetivo, en el supuesto de calificación concursal el cargo de administrador no es un cargo «honorífico» ni un título formal sino que implica una serie de derechos y deberes de obligado cumplimiento, y de igual manera en un supuesto del art. 48 LC frente a la invocación de que el demandado había asumido la administración formal de la concursada que evitaba la existencia de conducta dolosa o culposa, implica todo lo contrario, pues si su condición de administrador fue puramente formal, ello supone una clara negligencia y le hace manifiestamente culpable de cualquier situación irregular que haya conducido a la situación de insolvencia, pues hace patente su voluntario incumplimiento de todos los deberes que afectan a un administrador, ya que es totalmente rechazable el cumplimiento de la mera formalidad con dejación de los deberes que tan trascendental cargo implica; y aunque la jurisprudencia de TS se muestra cautelosa respecto de la coexistencia de administradores de hecho y de derecho, partiendo de la regla general de que responde de los danos derivados de la administración lesiva el administrador de derecho, también se admite la posible coexistencia de administradores de derecho puramente formales con otro $u$ otros de hecho, singularmente cuando se acredita que la designación formal tiene por objeto eludir la responsabilidad de quien realmente asume el control y gestión de la sociedad bajo la cobertura del apoderamiento..., por lo que se considera que es posible afirmar la responsabilidad de la persona que real y efectivamente ejerce las funciones de administrador de la sociedad, así como la del administrador/es de derecho, que figura/n como tal/es frente a terceros, y que de consuno actúan, al asumir este ultimo -sin cuestionarse su bondad- las decisiones del primero, ejecutándolas personalmente cuando ello es preciso.

\section{Bibliografía}

Montón Redondo, A y Montón García, M., El Nuevo Proceso Concursal, Valencia, Tirant lo Blanch, 2005 .

AznAR Giner, E., El procedimiento de declaración del concurso necesario del deudor. Doctrina, jurisprudencia $y$ formularios, $2^{\circ}$ edición, Valencia, Tirant lo Blanch, $20 \mathrm{I} 2$.

Villate Menadas, S., Elementos de Derecho Concursal, Valencia, Tirant lo Blanch, 20ir.

Rojo A., Campuzano, A.B. y Beltrán, E., La responsabilidad de los administradores de las sociedades mercantiles, $5^{a}$ edición, Valencia, Tirant lo Blanch, 2012. 